Abstract THU0353 - Table 1. Observed Change in MRI SIJ Structural Lesions, BL to Week 104

\begin{tabular}{|c|c|c|c|c|c|}
\hline Structural lesion & Cohort & $\begin{array}{l}\text { Decreased } \\
\mathrm{n} / \mathrm{N}(\%)\end{array}$ & $\begin{array}{l}\text { Increased } \\
\mathrm{n} / \mathrm{N}(\%)\end{array}$ & $\begin{array}{l}\text { Mean Difference } \\
\qquad(95 \% \mathrm{Cl})^{\dagger}\end{array}$ & $\begin{array}{c}\text { Mean differences (Control - ETN) } \\
(95 \% \mathrm{Cl})\end{array}$ \\
\hline \multirow[t]{2}{*}{ Erosion } & Control & $14 / 76(18.4)$ & 10/76 (13.2) & $-5.3 \%(-18.1,7.6)$ & $18.8 \%(3.5,34.1)^{\dagger \S}$ \\
\hline & ETN & $46 / 162(28.4)$ & $7 / 162(4.3)$ & $-24.1(-32.1,-16.0)$ & $17.8 \%(2.1,33.6)^{\ddagger \S}$ \\
\hline \multirow[t]{2}{*}{ Backfill } & Control & 2/76 (2.6) & $10 / 76(13.2)$ & $10.5 \%(1.7,19.3)$ & $-5.5 \%(-16.6,5.5)^{\dagger}$ \\
\hline & ETN & $1 / 162(0.6)$ & $27 / 162(16.7)$ & $16.0 \%(10.1,22.0)$ & $-3.7 \%(-15.2,7.8)^{\ddagger}$ \\
\hline \multirow[t]{2}{*}{ Fat metaplasia } & Control & $0 / 76(0)$ & $7 / 76(9.2)$ & $9.2 \%(2.6,15.9)$ & $1.8 \%(-6.6,10.2)^{\dagger}$ \\
\hline & ETN & $2 / 162(1.2)$ & 14/162 (8.6) & $7.4 \%(2.7,12.2)$ & $-2.4 \%(-11.2,6.4)^{\ddagger}$ \\
\hline \multirow[t]{2}{*}{ Ankylosis } & Control & $0 / 76(0)$ & $1 / 76(1.3)$ & $1.3 \%(-1.3,3.9)$ & $1.3 \%(-2.2,4.9)^{\dagger}$ \\
\hline & ETN & 2/162 (1.2) & $2 / 162(1.2)$ & $0 \%(-2.4,2.4)$ & $1.5 \%(-3.1,6.2)^{\ddagger}$ \\
\hline
\end{tabular}

Based on 2 of 3 readers assigning same category; otherwise considered no change. Some pts started with the lowest possible score and could not decrease. ${ }^{*}$ Percent pts with increase - percent pts with decrease. ${ }^{\dagger}$ One-way ANOVA. ${ }^{\ddagger}$ Adjusted for covariates listed in Methods. ${ }^{\S} P<0.05$.

yrs. Treatment effect was analyzed without and with adjustment for the baseline (BL) covariates of sex, symptom duration, smoking status, HLA-B27 status, ASDAS-CRP, SPARCC MRI SIJ score, and SIJ radiography score.

Results: At BL, pts with MRI images in the control (DESIR, $N=76$ ) and ETN (EMBARK, N=162) cohorts differed significantly in symptom duration, smoking status, ASDAS-CRP and SPARCC MRI SIJ score. The table presents structural lesion changes on MRI. The mean difference between control and ETN was significant for erosion (table). Figure shows cumulative probability plot.

Conclusions: This analysis confirms the slow rate of structural lesion progression in the SIJ over 2 yrs in nr-axSpA and suggests a lower rate of progression with ETN than without a TNF inhibitor.

References:

[1] Maksymowych WP, et al. J Rheumatol. 2015;42:79-86.

Disclosure of Interest: W. P. Maksymowych Grant/research support from: AbbVie, Pfizer, Sanofi, Consultant for: AbbVie, Amgen, Eli Lilly, Janssen Pharmaceutica, L.P, Novartis, Pfizer, Sanofi, UCB, M. Dougados Grant/research support from: Pfizer, Abbvie, UCB, Merck, Lilly, Sanofi, Consultant for: Pfizer, Abbvie, UCB, Merck, Lilly, Sanofi, R. G. Lambert Consultant for: Bioclinica, R. Landewe Grant/research support from: Abbott, Amgen, Centocor, Novartis, Pfizer, Roche, Schering-Plough, UCB, Wyeth, Consultant for: Abbott/Abbvie, Ablynx, Amgen, Astra-Zeneca, BMS, Celgene, Janssen (formerly Centocor), Galapagos, GSK, Novartis, Novo-Nordisk, Merck, Pfizer, Roche, Schering-plough, TiGenix, UCB, Wyeth, Employee of: Is a director of Rheumatology Consultancy BV, which is registered company under Dutch law, A. Molto Grant/research support from: Pfizer, UCB, Consultant for: Abbvie, BMS, MSD France- Merck, Pfizer, UCB, P. Claudepierre Grant/research support from: Pfizer, Roche-Chugai, MSD, Consultant for: Abbvie, BMS, Celgene, Janssen, Novartis, Merck, Pfizer, Roche, UCB, M. de Hooge: None declared, R. Bonin Shareholder of: Pfizer, Employee of: Pfizer, J. Bukowski Shareholder of: Pfizer, Employee of: Pfizer, H. Jones Shareholder of: Pfizer, Employee of: Pfizer, I. Logeart Shareholder of: Pfizer, Employee of: Pfizer, R. Pedersen Shareholder of: Pfizer, Employee of: Pfizer, A. Szumski Employee of: InVentiv Health, B. Vlahos Shareholder of: Pfizer, Employee of: Pfizer, D. van der Heijde Consultant for: AbbVie, Amgen, Astellas, AstraZeneca, BMS, Boeringer Ingelheim, Celgene, Daiichi, Eli-Lilly, Galapagos, Gilead, Janssen, Merck, Novartis, Pfizer, Regeneron, Roche, Sanofi, UCB, Employee of: Director of Imaging Rheumatology bv.

DOI: 10.1136/annrheumdis-2017-eular.1864

\section{THU0354 DISEASE WORSENING AND SAFETY IN PATIENTS SWITCHING FROM ORIGINATOR INFLIXIMAB TO BIOSIMILAR INFLIXIMAB (CT-P13) IN THE RANDOMIZED NOR-SWITCH-STUDY: EXPLORATIVE ANALYSIS IN SPA PATIENTS}

G.L. Goll ${ }^{1}$, I.C. Olsen ${ }^{1}$, N. Bolstad ${ }^{2}$, K.K. Jørgensen ${ }^{3}$, M. Lorentzen ${ }^{4}$, C. Mørk ${ }^{5}$, J. Jahnsen ${ }^{3}$, E.A. Haavardsholm ${ }^{1}$, T.K. Kvien ${ }^{1}$ on behalf of the NOR-SWITCH study group. ${ }^{1}$ Dept of Rheumatology, Diakonhjemmet Hospital;

${ }^{2}$ Biochemistry DNR, Oslo University Hospital, Oslo, ${ }^{3}$ Gastroenterology, Akershus
University Hospital, Lørenskog; ${ }^{4}$ Dermatology, Oslo University Hospital, Oslo; ${ }^{5}$ Dermatology, St Olav University Hospital, Trondheim, Norway

Background: The NOR-SWITCH study is a 52-week randomized, double-blind, non-inferiority, phase IV switch trial in patients with Crohn's disease (CD), ulcerative colitis (UC), spondyloarthritis $(\mathrm{SpA})$, rheumatoid arthritis (RA), psoriatic arthritis (PsA) and plaque psoriasis (Ps) on stable treatment with originator infliximab (Remicade ${ }^{\circledR}$, INX), funded by the Norwegian government. Previously, primary analyses of the pooled indications have been published ${ }^{1}$.

Objectives: To investigate efficacy, safety and immunogenicity in SpA patients treated with continuous INX vs patients switched to CT-P13 (biosimilar infliximab, Remsima $^{\circledR}$ ) in the NOR-SWITCH study (explorative analyses).

Methods: Patients were randomized 1:1 to continued INX or switch to CTP13. Serum drug levels were analyzed by automated in-house assay. The primary endpoint was disease worsening according to disease-specific composite measures and/or consensus between investigator/patient. Exploratory subgroup analyses examined disease worsening and safety in SpA. The primary endpoint was analysed by logistic regression, adjusted for diagnosis and disease duration. Results: Demographics, occurrence of disease worsening, change in disease measures and treatment-emergent adverse events (TEAE) were similar (Table), as were serum drug levels for INX and CT-P13 (Figure).

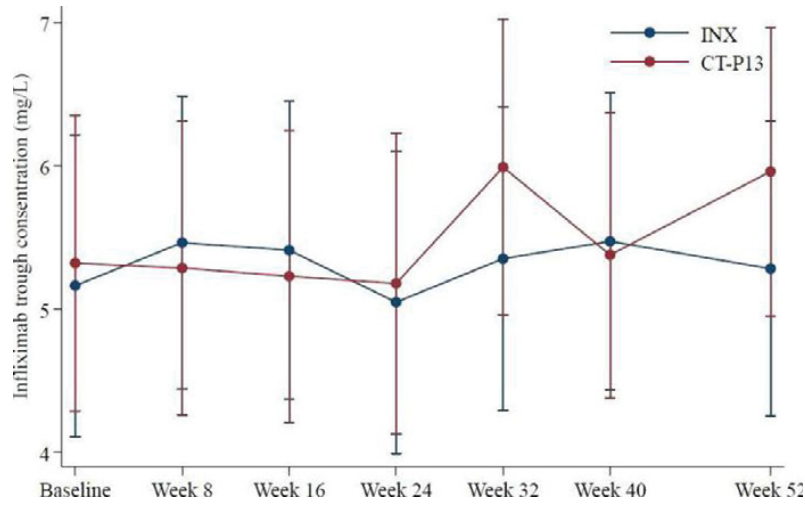

Conclusions: Explorative analyses in the NOR-SWITCH study showed similar efficacy, drug levels and safety in SpA patients switched to CT-P13 as those on continuous INX. The study was not powered to show non-inferiority within each diagnosis.

References:

[1] Jørgensen $\mathrm{KK}$ et al. Switching from originator infliximab to biosimilar CT-P13 compared to maintained treatment with originator infliximab (NOR-SWITCH): a 52-week randomised double-blind non-inferiority trial. The Lancet, in press. Disclosure of Interest: G. Goll Consultant for: AbbVie, Boehringer Ingelheim,

Abstract THU0354 - Table 1. Demographics, baseline characteristics (FAS), percentage of patients with disease worsening, change in disease measures during 52 weeks follow-up (PPS)

\begin{tabular}{|c|c|c|c|}
\hline Demographics, baseline characteristics & INX & CT-P13 & \\
\hline Total number of SpA patients PPS/FAS & $43 / 45$ & $42 / 46$ & \\
\hline Age (years) mean (SD) & $50.0(10.3)$ & $52.8(10.8)$ & \\
\hline Females & $7(16 \%)$ & $8(17 \%)$ & \\
\hline Duration of ongoing INX treatment (years) mean (SD) & $8.6(3.1)$ & $8.7(3.2)$ & \\
\hline Immunosuppressive co-medication & $15(33 \%)$ & $10(22 \%)$ & \\
\hline HLA B27 pos & $31(94 \%)$ & $33(87 \%)$ & \\
\hline Disease worsening & & & $95 \% \mathrm{Cl}$ of group difference after 52 weeks \\
\hline All study patients & $53(26.2 \%)$ & $61(29.6 \%)$ & $-12.7-3.9 \%$ \\
\hline $\mathrm{SpA}$ & $17(39.5 \%)$ & $14(33.3 \%)$ & $-14.5-27.2 \%$ \\
\hline \multicolumn{4}{|l|}{ Change in disease measures from baseline } \\
\hline Physician Global Assessment of Disease Activity (0-10) & $-0.1(1.4)$ & $-0.5(1.3)$ & $0.53-0.53$ \\
\hline Patient Global Assessment of Disease Activity (0-10) & $0.1(2.2)$ & $-0.4(1.8)$ & $-0.08-0.62$ \\
\hline $\log _{10}$ erythrocyte sedimentation rate $(\mathrm{mm} / \mathrm{h})$ & $0.0(0.3)$ & $-0.0(0.3)$ & $-0.14-0.06$ \\
\hline $\log _{10}$ C-reactive protein $(\mathrm{mg} / \mathrm{L})$ & $-0.0(0.4)$ & $-0.1(0.4)$ & $-0.11-0.15$ \\
\hline ASDAS & $0.1(0.6)$ & $-0.2(0.7)$ & $-0.27-0.24$ \\
\hline BASDAI & $0.3(1.0)$ & $-0.2(1.4)$ & $-0.50-0.47$ \\
\hline TEAE (FAS) & 116 & 102 & \\
\hline
\end{tabular}

Data are $\mathrm{n}(\%)$, mean (SD) or median (25-75 percentiles). 95\% Cl, 95\% confidence interval of the adjusted treatment difference. BASDAI, Bath Ankylosing Spondylitis Disease Activity Index. ASDAS, Ankylosing Spondylitis Disease Activity Score. FAS, Full Analysis Set. PPS, Per Protocol Set. TEAE, treatment emergent adverse events. 
Orion Pharma, Novartis, Pfizer, I. Olsen: None declared, N. Bolstad: None declared, K. Jørgensen Consultant for: Celltrion, Intercept, AbbVie, Tillott, M. Lorentzen: None declared, C. Mørk Consultant for: Cellgene, AbbVie, Galderma Nordic, ACOhud, Novartis, LEOPharma, J. Jahnsen Consultant for: Celltrion, Orion Pharma, Pfizer, MSD, AbbVie, Takeda, Napp Pharma, AstroPharma, E. Haavardsholm Consultant for: AbbVie, UCB, Pfizer, MSD, Roche, T. Kvien Consultant for: Biogen, BMS, Boehringer Ingelheim, Celltrion, Eli Lily, Epirus, Hospira, Merck-Serono, Novartis, Orion Pharma, Pfizer, Sandoz, UCB DOI: 10.1136/annrheumdis-2017-eular.4438

\section{THU0355 INFLUENCE OF ADALIMUMAB AND SULFASALAZINE ON STRUCTURE OF HYALINE CARTILAGE OF HIP JOINTS IN PATIENTS WITH ANKYLOSING SPONDILITIS}

A. Petrov, H. Zayaeva, A. Petrov. Medical Academy named after Georgievsky, Crimean Federal university named after V.I. Vernadsky, Simferopol, Russian Federation

Background: The impairment of hip joints has significant prognostic value on functional status of patients with Ankylosing spondylitis (AS) [1]. One of possible yearly marker of hip joints structure damage in patients with AS may be changing in volume of hyaline cartilage [2]. But clinical significance of this marker in monitoring of hip joint structure changes during treatment is underinvestigated.

Objectives: To investigate changes in width of hyaline cartilage of hip joints in patients with AS under treatment with sulfasalazine and adalimumab during 12 month.

Methods: The 53 patients with AS (42 male, 9 female, average age is 37.6 years old, duration of disease is $14-152$ month) were included into study. All patients were treated by NSAIDs and sulfasalazine ( $2 \mathrm{~g}$ per day) at least 3 month before study. In treatment of 27 patients (1st group) was added adalimumab (40 $\mathrm{mg}$ subcutaneously every 2 weeks), other 26 patients (2nd group) were left on previous treatment regime. Patients were observed during 12 months of treatment including measurements of pain visual analog scale (VAS) in hip movements, maximal distance between ankles, pelvic X-ray and sonography of hip joints by 10-18 MHz probe. BASRI-Hips index was applied for radiographic estimation of structural damage of hip joints [3]. During sonography width of hip joint capsule and hyaline cartilage were measured. The Mann-Whitney-U test was used for comparison of changes in clinical and sonographic data between two groups of patients.

Results: After 12 month treatment period in patients of 1 st group in comparison with patients of 2nd group more significant decrease of pain VAS during hip movements (on 27.3 [18.8; 32.5] mm vs $4.7[0.5 ; 9.6] \mathrm{mm}, \mathrm{p}<0,01$ ), increase of maximal distance between ankles (on 124.3 [92.3;145.6] $\mathrm{mm}$ vs 3.5 [1.2; 6.5] $\mathrm{mm}, \mathrm{p}<0,05$ ) and decrease of joint capsule width (on $2.4[1.0 ; 3.6] \mathrm{mm}$ vs 0.4 [0.0;1.1] mm, $p<0,05)$ had been determined. In patients of 1st group width of hyalinic cartilage had been increased on $0.15[0.4 ; 0.22] \mathrm{mm}$, while in patients of 2 nd group width of hyalinic cartilage had been decreased on $0.8[0.0 ; 1.4]$ $\mathrm{mm}(p<0,05)$. These cartilage changes were accompanied by decrease of mean BASRI-Hips index on 1 point in 2nd group and absence of changes of BASRI-Hips index in 1st group. The correlation between changes in width of hip hyalinic cartilage and pain VAS during movement in hip joints $(r=-0.52[0.38 ; 061])$ and maximal distance between ankles $(r=+0.47[0.32 ; 0.60])$ had been revealed.

Conclusions: Treatment with adalimumab leads to decrease of clinical and sonographic signs of coxitis and improvement of hyaline cartilage structure. The increase of width of hip hyalinic cartilage correlates with clinical effect of treatment of coxitis in patients with AS. More prolonged observation is needed for analysis of correlation between changes in hyaline cartilage structure and radiographic progression of hip joints damage in AS.

References:

[1] Baraliakos X., Braun J. Hip involvement in ankylosing spondylitis: what is the verdict? Rheumatology 2009;49(1):3-4.

[2] Maksymowych W.P. Ankylosing spondylitis - at the interface of bone and cartilage. J Rheumatol 2000;27(10):2295-301.

[3] MacKay K, Brophy S, Mack C, et al. The development and validation of a radiographic grading system for the hip in ankylosing spondylitis: the bath ankylosing spondylitis radiology hip index. J Rheumatol. 2000;27:2866-72.

Disclosure of Interest: None declared

DOI: 10.1136/annrheumdis-2017-eular.1672

\section{THU0356 THE RANK OF ADMINISTRATION AND NOT THE MOLECULE HAS AN IMPACT ON THE ANTI TNF TREATMENT RESPONSE IN AXIAL SPA}

A. Moltó, A. Etcheto, L. Gossec, S. Perrot, N. Boudersa, P. Claudepierre, N. Roux, F. Berenbaum, A. Martin, L. Sparsa, P. Coquerelle, M. Soubrier, M. Dougados. Predict-SpA Study Group, Paris, France

Background: Five different sub-cutaneous TNF alpha blockers (TNFb) are available for the treatment of NSAID-refractory and active axial spondyloarthritis (axSpA). The efficacy of these drugs in axSpA has been well reported in several RCT and real-life studies separately or as a group, but only very few head-to-head studies have compared each molecule's treatment effect in axSpA. Also, some data suggest that TNFb treatment effect in patients failing to a first TNFb is poorer than in TNFb-naïve patients, but some other suggest that response to a second TNFb might be comparable.

Objectives: to describe TNFb prescription and treatment response of each TNFb, and to compare treatment response in TNFb- naïve/not naïve axSpA patients in a real-life setting.

Methods: Prospective, multicenter, usual care study with 2 visits (baseline and 12 weeks after TNFb initiation, Predict-SpA study, ClinicalTrials.gov: NCT03039088)). Patients: axSpA patients (diagnosis according to treating rheumatologist) initiating a TNFb. Data collection: Patients and disease characteristics at baseline. Previous exposure to TNFb was collected. Disease activity and function measures were collected at both visits. The choice of the TNFb to be started during the trial was at the treating rheumatologist's discretion. Statistical analysis: effectiveness was defined by the BASDAI50 response. Non-responder imputation and baseline observation carried forward imputation (for binary and continuous outcome variables, respectively) were performed for patients who discontinued the TNFb treatment between baseline and the follow-up visit.

Results: Among the 527 patients enrolled in the study, 508 patients were included in the analysis (1 patients was excluded due to missing data on all disease activity measures at baseline, and 18 patients were excluded due loss of follow-up between baseline and the follow-up visit). Mean age was $41.4( \pm 11.6), 237$ (47\%) were women, with a $6.1+8.5$ mean disease duration $377 / 508(74 \%)$ were TNFb-naïve while $66(13 \%), 35(7 \%), 19(3.7 \%), 8(2 \%)$ and $3(1 \%)$ had previously received, 1,2, 3, 4 and $>4 \mathrm{TNFb}$, respectively.

In the whole study population the most frequently prescribed TNFb was etanercept $(197(39 \%))$, followed by adalimumab $(131(26 \%))$, golimumab (88 $(17 \%))$, infliximab $53(10 \%)$ and certolizumab (39 (8\%)); the same order was observed in TNFb naïve patients; however, in patients previously exposed to TNFb, the most frequently prescribed TNFb was infliximab (31 (24\%)) followed by golimumab $(29(22 \%))$, adalimumab $(29(22 \%))$, certolizumab $(22(17 \%))$ and etanercept $(20(15 \%))$.

BASDAI50 responses were comparable for all TNFb molecules: 52\%, 52\%, $48 \%, 53 \%$ and $49 \%$ for etanercept, adalimumab, golimumab, infliximab and certolizumab, respectively.

BASDAI 50 response was comparable in patients TNFb-naïve and patients previously exposed to only 1 previous TNFb $(53 \%$ vs. $52 \%$, for naĩve vs. nonnaïve patients) but significantly decreased after (i.e. $37 \%$ and $36 . \%$ for patients previously exposed to 2 and to 3 or more $\mathrm{TNFb}$ )

Conclusions: this study suggests that the TNFb treatment response is similar across the different available molecules but this treatment response decreased in case of a previous use of two TNFb.

Acknowledgements: This study was conducted thanks to an unrestricted grant from MSD

Disclosure of Interest: None declared

DOI: 10.1136/annrheumdis-2017-eular.2678

\section{THU0357 NO SPECIFIC IMPACT OF CONCOMITANT FIBROMYALGIA ON THE ANTI TNF TREATMENT EFFECT IN AXIAL SPONDYLOARTHRITIS PATIENTS WITHOUT RADIOGRAPHIC STRUCTURAL DAMAGE OR OBJECTIVE SIGNS OF INFLAMMATION}

A. Moltó, A. Etcheto, L. Gossec, S. Perrot, N. Boudersa, P. Claudepierre, N. Roux, F. Berenbaum, A. Martin, L. Sparsa, P. Coquerelle, M. Soubrier, M. Dougados. Predict-SpA Study Group, Paris, France

Background: Currently, the European Medicine Agency (EMA) is recommending the use of anti-TNF in case of active NSAID refractory axial (ax) spondyloarthritis $(\mathrm{SpA})$ only in the presence of either structural radiographic damage of the sacroiliac Joints (SIJ) or objective signs of inflammation (either elevated CRP or inflammation at MRI-SIJ) probably mainly because of the fear of a concomitant fibromyalgia (FM).

Objectives: To evaluate the interaction of a concomitant FM on the anti-TNF response with regard to the application of the EMA recommendation

Methods: Study design: Prospective, multicenter, longitudinal (12 weeks) open trial (Predict-SpA, ClinicalTrials.gov: NCT03039088). Patients (pts): axSpA requiring an anti-TNF. Data collected: At baseline, 1/Radiographic SIJ damage 2/ MRI-SIJ inflammation 3/ Elevated CRP 4/ FM according to the FiRST (Fibromyalgia Rapid Screen Test) questionnaire. At baseline and after 12 weeks of therapy: BASDAI. Statistical analysis: Non Responder Imputation (NRI), Baseline Carried Forward Technic (BOCF) in case of missing data. Interaction test between the presence of FM and the fulfillment of the EMA recommendation (defined by the presence of either structural radiographic damage of the SIJ or objective signs of inflammation (either elevated CRP or inflammation at MRI-SIJ)) on the anti TNF treatment response (BASDAI50)

Results: Of the 508 enrolled pts (females: $46.7 \%$, age: $41.4+11.6$ years old, HLA B27 positive: $57.5 \%$, X-Ray sacroiliitis: $53.2 \%$, inflammation at MRI-SIJ: $52.0 \%$ ), only 59 had no structural damage at SIJ-X-Rays and no inflammation at MRI-SIJ (12\%). A concomitant FM was noticed in $42 \%$ vs $37 \%$ of pts treated in accordance vs not with the EMA recommendation, respectively $(\mathrm{p}=0.44)$. The anti-TNF treatment effect was higher in the groups of pts treated in accordance (vs not) with the EMA recommendation (BASDAI 50: $52 \%$ vs 39\%, respectively; $\mathrm{p}=0.054$ ). There was a trend (but not statistically significant) suggesting an interaction of the concomitant FM on the anti TNF treatment response with regard 